Volume 2

Issue 4 -- Integrative Medicine

Article 12

$11-20-2015$

\title{
Echocardiographic Predictors of Admission Among Patients With Heart Failure With Reduced Ejection Fraction
}

Chi C. Cho

Yang Shi

Robyn Shearer

Nasir Z. Sulemanjee

Dianne L. Zwicke

T. Edward Hastings

Omar M. Cheema

Vinay Thohan

Follow this and additional works at: https://aah.org/jpcrr

Part of the Cardiology Commons, Cardiovascular Diseases Commons, and the Other Analytical, Diagnostic and Therapeutic Techniques and Equipment Commons

\section{Recommended Citation}

Cho CC, Shi Y, Shearer R, Sulemanjee NZ, Zwicke DL, Hastings TE, Cheema OM, Thohan V.

Echocardiographic predictors of admission among patients with heart failure with reduced ejection fraction. J Patient Cent Res Rev. 2015;2:204. doi: 10.17294/2330-0698.1222

Published quarterly by Midwest-based health system Advocate Aurora Health and indexed in PubMed Central, the Journal of Patient-Centered Research and Reviews (JPCRR) is an open access, peer-reviewed medical journal focused on disseminating scholarly works devoted to improving patient-centered care practices, health outcomes, and the patient experience. 
worker consultation and diagnoses of respiratory issues and dementia.

Conclusion: A promising automated model generated by EHR data to predict 30-day readmissions and mortality among hospitalized older adults, these findings will be used by the health care system to incorporate a real-time alert into physician workflow. Efforts to improve care will include interventions targeted at the highest-risk group.

\section{FIRST PLACE POSTER (tie)}

See page 217 for citation.

\section{SECOND PLACE POSTER}

See page 217 for citation.

\section{THIRD PLACE POSTER}

\section{Echocardiographic Predictors of Admission Among Patients With Heart Failure With Reduced Ejection Fraction}

Chi C. Cho, Yang Shi, Robyn Shearer, Nasir Z. Sulemanjee, Dianne L. Zwicke, T. Edward Hastings, Omar M. Cheema, Vinay Thohan

\section{Aurora Research Institute, Aurora Health Care; Aurora Cardiovascular Services, Aurora Health Care}

Background: Congestive heart failure afflicts 5.7 million people in the United States with annual incidence of 600,000 and mortality of 280,000. Heart failure accounts for greater than 1 million hospitalizations annually and the single largest inpatient Medicare expense. As the U.S. population ages and greater emphasis is placed on population health as a means to bend projected health care expenditures, large health care organizations will need to develop algorithms to identify patients at high risk with heart failure and possibly preempt hospitalizations. Doppler echocardiography is routinely performed in clinical assessment of severe heart failure.

Purpose: We sought to determine echocardiographic parameters that predict 1-year cardiac events among ambulatory patients diagnosed with heart failure with reduced ejection fraction.

Methods: A retrospective single-institution investigation identified 485 patients aged $<75$ years with left ventricular ejection fraction $<35 \%$. Kaplan-Meier method was used to identify parameters that corresponded with primary endpoint of hospitalization, emergency room visit or death.

Results: High risk of primary endpoint could be segregated into four groups by presence of one or more of the following parameters $(0,1,2,3)$ : mitral inflow $\mathrm{E} / \mathrm{A}$ ratio $>1.5$, mitral E-wave deceleration time $<160 \mathrm{~ms}$ or peak tricuspid regurgitant (TR) velocity $>3 \mathrm{~m} / \mathrm{s}$. Event-free survival was significantly lower in high-risk group compared to low-risk group $(\mathrm{P}=0.002)$. The 30-day hospitalization rates among those with all three factors compared to those without was $37.5 \%$ and $17.3 \%, \mathrm{P}=0.018$.
Conclusion: Presence of routine echocardiographic parameters, including E/A ratio $>1.5$, E-wave deceleration time $<160 \mathrm{~ms}$ and TR velocity $>3 \mathrm{~m} / \mathrm{s}$, is associated with high cardiovascular event rates among nonhospitalized ambulatory patients with reduced ejection fraction heart failure.

RIESELBACH DISTINGUISHED PAPER \#1 Cardiopulmonary Exercise Testing-Based Algorithm and Its Usefulness in Clinical Cardiology

Mirza Nubair Ahmad, Syed Hasan Yusuf, Rafath Ullah, Mary Ellis, Haroon Yousaf, Timothy E. Paterick, Khawaja Afzal Ammar

Aurora Cardiovascular Services, Aurora Health Care; Division of Pulmonary and Critical Care Medicine, Medical College of Wisconsin

Background: Only cardiopulmonary exercise (CPX) testing provides information on the ability of the cardiovascular system to meet the body's metabolic demands in terms of oxygen consumption $\left(\mathrm{VO}_{2}\right)$ and carbon dioxide production $\left(\mathrm{VCO}_{2}\right)$. However, $\mathrm{CPX}$ testing is underutilized by cardiologists due to complex diagnostic algorithms involving up to 30 variables as well as lack of validation studies. In addition, CPX also provides oxygen $\left(\mathrm{O}_{2}\right)$ pulse as a continuous measure of stroke volume, which is its superiority to other stress modalities in which systolic function is measured at peak stress and rest. In the literature, it has been recommended that a composite criterion (combining peak $\mathrm{O}_{2}$ pulse with $\mathrm{O}_{2}$ pulse curve pattern) should be used to assess the cardiac function. Furthermore, the operating test characteristics and optimal cutoff of $\mathrm{O}_{2}$ pulse for distinguishing cardiac from noncardiac causes of exercise limitation also are unknown.

Purpose: We tested whether a 6-variable algorithm would discriminate cardiac from noncardiac causes of dyspnea when compared with comprehensive CPX testing to promote its use by cardiologists. We also tested several cutoff points along with the composite criterion against the clinical standard to define the optimal $\mathrm{O}_{2}$ pulse cutoff point.

Methods: Consecutive patients $(\mathrm{n}=54)$ referred for dyspnea underwent CPX test consisting of pulmonary $\left(\mathrm{VO}_{2}, \mathrm{VCO}_{2}\right.$, 22 additional variables and invasive measurement of lactate and blood gases at peak and baseline) and cardiac (exercise ECG, heart rate and blood pressure response) components as well as medical record evaluation. Patients were categorized as normal or abnormal by an experienced pulmonologist. Abnormal patients were further categorized according to cause of dyspnea (cardiac, pulmonary, deconditioning, poor effort and miscellaneous). Subsequently, the 6-variable algorithm was applied by a cardiologist blinded to all of the information from CPX tests, and the patients were categorized similarly. The 6 variables used were peak $\mathrm{O}_{2}$ uptake, peak respiratory exchange ratio, $\mathrm{O}_{2}$ pulse, heart rate reserve, breathing reserve (1 - [peak ventilation (VE) / maximal voluntary ventilation]) and ventilatory efficiency $\left(\mathrm{VE} / \mathrm{VCO}_{2}\right)$. Seven $\mathrm{O}_{2}$ pulse reference cutoff points 